\title{
Implications of Reassigning Patients for the Medical Home: A Case Study
}

\author{
Katie Coleman, MSPH \\ Robert J. Reid, MD, PbD \\ Eric Jobnson, MS \\ Clarissa Hsu, PbD \\ Tyler R. Ross, MA \\ Paul Fishman, $\mathrm{PbD}$ \\ Eric Larson, $M D, M P H$ \\ Group Health Research Institute, \\ Seattle, Washington
}

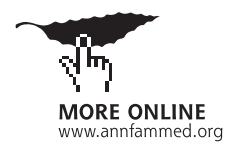

Conflicts of interest: none reported

AIC Annals Journal Club selection; see inside back cover or http://www. annfammed.org/AJC/.

\section{CORRESPONDING AUTHOR}

Katie Coleman, MSPH

Group Health Research Institute

1730 Minor Ave, Suite 1600

Seattle, WA 98101

coleman.cf@ghc.org

\begin{abstract}
PURPOSE Improving patient-doctor continuity is one goal of the medical home, but achieving this goal may require physicians to reduce panel size. This article examines the impact on patient experience and utilization of Group Health Cooperative's process of reassigning patients to new physicians as part of their medical home demonstration project.
\end{abstract}

METHODS This work represents a subanalysis of the Group Health medical home pilot evaluation. Study participants include 8,005 adults who received primary care in 2006 and 2007 at an urban practice owned and operated by a not-forprofit integrated delivery system. Approximately one-quarter of patients were selected to be reassigned to a new physician. Primary care, emergency department, secure messaging, and telephone utilization were captured through automated sources. Patients' experience was measured before and after implementation of the medical home for a subset of 1,098 patients.

RESULTS Patients who were retained by their existing physicians were older, sicker, and had longer preexisting patient-doctor relationships. After reassignment, reassigned patients were less likely to use primary care services but equally likely to use the emergency department. They were no less satisfied with their care experience.

CONCLUSIONS Informational and managerial continuity may mitigate deleterious effects of reassignment, but more must be done to actively bind reassigned patients to the medical home to improve relational continuity with younger, healthier patients.

Ann Fam Med 2010;8:493-498. doi:10.1370/afm.1190.

\section{INTRODUCTION}

$\mathrm{P}$ rofessional associations, policy makers, and health care providers are recognizing the many, well-documented challenges limiting US primary care's capacity to deliver high-quality services. ${ }^{1-5}$ There is growing enthusiasm among commercial health plans and other private and public entities for implementing a patient-centered medical home model $(\mathrm{PCMH})$ to improve clinical quality, strengthen primary care, improve patient experience, and reduce costs. ${ }^{6-13}$ According to PCMH principles, practices must redesign several components of care delivery, including establishing a regular physician or source of care for each patient and understanding patient populations, to provide accessible, high-quality, coordinated care. ${ }^{14-16}$ Achieving these goals requires practices to make a deliberate attempt to identify a group of patients for whom a physician or team is responsible and to engender meaningful relationships with that complement of patients. One underappreciated consequence of redesigning a primary care practice around the $\mathrm{PCMH}$ is that for many practices where physicians have large or unbalanced workloads, patients may need to be shifted from one physician to another and engender new relationships with different physicians. ${ }^{14,17,18}$ 
Group Health Cooperative, a large, nonprofit, integrated delivery system, is among the first organizations to operationally define, implement, and comprehensively evaluate a medical home redesign initiative for all adult patients enrolled in an urban primary care practice. ${ }^{18}$ The initiative resulted in improved patient experience, reduced staff burnout, improved clinical quality, and 29\% fewer emergency department visits in the intervention site when compared with control sites. Despite the substantial investment needed to implement the $\mathrm{PCMH}$, the pilot demonstrated savings of $\$ 10.30$ per member per month after 21 months. ${ }^{19}$

As part of the medical home pilot, Group Health aimed to strengthen doctor-patient relationships by reducing physician panel size, expanding standard visit time from 20 to 30 minutes, and allocating an hour each day for secured messaging and telephone communication with patients. Despite overall improvements in patient experience and utilization among patients in the medical home pilot site, ${ }_{1}^{19}$ we anticipated that patients who had been reassigned to new physicians may have experienced a transitory downside in their care. We noted a lack of research evaluating the impact on patients of the process of adjusting patient panels as part of the medical home. ${ }^{20}$ This supplementary analysis to Group Health's PCMH evaluation presents the first quantitative examination of the potential unintended consequences of reassigning patients to new physicians as part of medical home practice redesign.

\section{METHODS}

We base our analysis and interpretation of findings on Haggerty and colleagues' conceptual model of continuity that was developed by means of a systematic review of the literature with multidisciplinary expert input. ${ }^{21}$ This framework proposes 3 conceptually distinct elements of information, management, and relational continuity and suggests that impact of each type of continuity on patient experience and outcomes depends on the context of care. ${ }^{22}$ This conceptual approach builds on existing literature that demonstrates the importance of continuity to improved patient satisfaction, ${ }_{1}^{23}$ health behaviors ${ }^{24}$ health outcomes, ${ }^{25}$ reduced use of services, ${ }^{26}$ and lower total costs. ${ }^{27}$

\section{Description of Group Health's Reassignment Process}

The reassignment process began in the fall of 2006after planning for the medical home pilot concluded but before implementation of the key practice changes began. The goal was to reduce the unadjusted panel size to 1,800 individual patients for a full-time-equivalent (FTE) physician. Before reassignment, physicians carried panel loads that ranged from 1,450 to 3,281 patients per 1.0 FTE. To achieve the new panel targets, 2 new physicians were hired, and the 6 existing physicians changed their FTE-adjusted panel sizes by an average of $-23 \%$ in 2007 (range, $-39 \%$ to $+25 \%$ ).

Physicians were asked to review their patient panels and identify patients for whom they believed ongoing relationships were clinically important. A random sample of the remaining patients on each physician's panel received a letter telling them that they had been selected for reassignment as part of the medical home practice redesign and introducing them to their new physician. Patients who were selected for reassignment were advised to call Group Health's customer service department if they had any questions or concerns and were reminded that they could select a different physician at any time. By December 2006, $80 \%$ of the panel redistribution had occurred and the process was viewed as complete.

\section{Study Population}

Study participants included adults aged 18 to 101 years who were enrolled in the pilot clinic for at least 180 days in 2006 and at least 90 days in 2007. Annualized utilization data for both 2006 and 2007, including primary care and emergency department/urgent care visits, were derived from the Group Health automated information system, which captures health services use across facilities and from external claims. Primary care visits included all in-person visits to family physicians, general internists, physician assistants, and nurse practitioners. Secure messages and telephone encounters represent the count of contacts in each medium between patient and physician, regardless of the initiating party. Morbidity was measured using a diagnosis-based DxCG (Verisk Health, Waltham, Massachusetts) case mix score, categorized into tertiles, which were calculated with automated diagnosis data from the baseline year (2006). DxCG scores categorize and weight diagnoses into clinical morbidity groups with similar resource expenditure. ${ }^{28} \mathrm{We}$ used the Bice-Boxerman continuity of care (COC) index to measure continuity of care. ${ }^{29}$ The COC index measures the concentration of care with a single physician and accounts for the number of visits and different physicians. Because continuity measures may be unreliable for patients who make few visits, ${ }^{30}$ we limited this measure to adult patients with 3 or more visits in the study period. The duration of the doctor-patient relationship was measured as the number of years each patient was in his or her physician's panel before September 30, 2006.

To capture information on patient experience, a 41 -question patient survey questionnaire that included 5 subscales from the Ambulatory Care Experiences Survey-Short Form (ACES-SF) and 2 
subscales from the Patient Assessment of Chronic Illness Care (PACIC) was mailed to a random sample of 2,100 adults aged 21 through 85 years enrolled at the PCMH demonstration clinic between September 18 and October 2, 2006. ${ }^{31-33}$ This instrument is available online as a Supplemental Appendix, at http://

Al www.annfammed.org/cgi/content/full/8/6/493/DC1.

Patients were asked to report their overall health status using a single global health rating (excellent, very good, good, fair, or poor). Respondents received follow-up questionnaires 12 months later. At baseline, the patient survey yielded a 59\% response rate. Twelve months later, $73.8 \%$ of reassigned patients and $78.9 \%$ of not reassigned patients who had completed the first questionnaire responded to the follow-up questionnaire. Adjusting for baseline differences between responders and nonresponders did not significantly affect the results. Data collection and analyses were approved by the Group Health Human Subjects Review Committee on September 13, 2006, as part of the Evaluation of the Medical Home Model (MHM) Initiative at Group Health Cooperative.

\section{Analytical Methods}

We used linear regression models for the questionnairebased ACES-SF and PACIC subscales, adjusting for sex, age, self-reported education and health status, reassignment to a new vs existing doctor, and the baseline measure. Missing follow-up measures were addressed by multiple imputation, using participants' completed questionnaire responses, utilization, and enrollment data. Because this study is a supplementary analysis to the Group Health PCMH evaluation, the survey subanalyses are not independently powered to detect between-group differences. Health care utilization was analyzed using a generalized linear model with a log link and Poisson variance structure with an adjustment for overdispersion; no within-physician correlation was observed for these measures. Patients who were reassigned were compared with those who were not, regardless of eligibility. Sensitivity analyses showed little likelihood of confounding resulting from reassignment eligibility. These models controlled for the major factors physicians used to determine who to retain in their panels, including patient sex, age, DxCG morbidity score, duration with their primary care physician before reassigning, and 2006 utilization. Analyses were conducted using Stata 10.1 (StataCorp LP, College Station, Texas).

\section{RESULTS}

As part of Group Health's PCMH pilot demonstration, physicians were given a list of their patients and were able to select those they believed should be retained in their panel. This step provided a chance for physicians to select patients for whom relational continuity was considered so clinically important to the patients' wellbeing that they should be excluded from potential reassignment (personal communication, Practice Manager, September 17, 2009). Though this was the only step before patients were randomly selected for reassignment, it resulted in significant differences between patients who were reassigned and those who were not (Table 1).

Physicians retained in their panels those patients who were sicker and with whom they had longer relationships. Reassigned patients were more often younger, healthier males who utilized approximately one-third to one-half fewer primary care, secure message, telephone, and emergency department/urgent care visits in the baseline year compared with those not reassigned.

Reassigned patients' experience of care at follow-up appeared to be no lower on the ACES-SF and PACIC subscales after accounting for baseline experience and whether the patient was reassigned to a new or existing physician (Table 2). Furthermore, Cohen's d effect sizes were calculated (data not shown), but none was significant. Because this study is a subanalysis, we may be underpowered to detect a clinically significant difference. No differences in patient disenrollment throughout 2007 were seen between the 2 groups $(5.6 \%$ not reassigned vs $4.2 \%$ reassigned $P=.711$ ); the measure is too variable to establish any definitive conclusions.

After controlling for baseline patient characteristics and utilization, reassigned patients utilized in-person primary care less often in 2007 than did not reassigned patients $(P=.004)$. We were unable to detect differences in emergency department and urgent care visits $(P=.143)$.

\section{DISCUSSION}

The differences between the reassigned and the not reassigned patients in terms of longitudinal relational continuity were striking. When given the chance to retain patients in their panels, physicians chose those who were oldest, sickest, and with whom they had the longest relationship. This finding bolsters Hjortdahl's conclusion that a physician's extensive knowledge of his or her patients and feeling of responsibility toward them increase with time and with a greater density of visits. ${ }^{34}$

It also confirms that continuity matters for physicians ${ }^{35}$ and patients, ${ }^{36}$ especially more vulnerable patients. ${ }^{37}$ Contrary to policy concerns, physicians in this demonstration project chose to retain those patients who were older and sicker. Group Health physicians are paid based on a salary, and panel size expectations are not risk adjusted, therefore, physicians face no financial benefit to retain patients with com- 
Table 1. Baseline Characteristics of Not Reassigned and Reassigned Patients

\begin{tabular}{|c|c|c|c|}
\hline Demographic Characteristics & $\begin{array}{c}\text { Not } \\
\text { Reassigned }\end{array}$ & Reassigned & $\begin{array}{c}P \\
\text { Value }^{a}\end{array}$ \\
\hline Eligible patients from automated data, $n$ & 6,188 & 1,817 & \\
\hline \multicolumn{4}{|l|}{ Age in years, $n(\%)$} \\
\hline$\leq 35$ & $1,137(18.4)$ & $456(25.1)$ & $<.001$ \\
\hline $36-45$ & $713(11.5)$ & $333(18.3)$ & \\
\hline $46-55$ & $1,199(19.4)$ & $411(22.6)$ & \\
\hline $56-65$ & $1,377(22.3)$ & $359(19.8)$ & \\
\hline $66-75$ & $870(14.1)$ & $147(8.1)$ & \\
\hline$\geq 76$ & $892(14.4)$ & $111(6.1)$ & \\
\hline Male sex, $\mathrm{n}(\%)$ & $2,500(40.4)$ & $962(52.9)$ & $<.001$ \\
\hline \multicolumn{4}{|l|}{ DxCG case mix score, n (\%) } \\
\hline Low morbidity $(0.10-0.87)$ & $1,732(28.0)$ & $790(44.0)$ & $<.001$ \\
\hline Moderate morbidity (0.97-1.85) & $2,092(33.8)$ & $641(35.3)$ & \\
\hline High morbidity (1.85-106) & $2,364(38.2)$ & $377(20.8)$ & \\
\hline \multicolumn{4}{|l|}{$\begin{array}{l}\text { Length of relationship with primary care } \\
\text { physician, } \mathrm{n}(\%)\end{array}$} \\
\hline$<1$ year & $771(12.5)$ & $274(15.1)$ & $<.001$ \\
\hline $1-5$ years & $2,300(37.2)$ & $1,025(56.4)$ & \\
\hline $5+$ years & $3,117(50.3)$ & $518(28.5)$ & \\
\hline Continuity of care index, mean (SD) & $0.495(0.382)$ & $0.442(0.401)$ & .001 \\
\hline $\begin{array}{l}\text { Patients assigned to newly hired doctors, } \\
\mathrm{n}(\%)\end{array}$ & $356(5.8)$ & $1,217(67.0)$ & $<.001$ \\
\hline \multicolumn{4}{|c|}{ Information from baseline patient survey (2006) } \\
\hline Patient survey complete, $\mathrm{n}$ & 938 & 160 & \\
\hline \multicolumn{4}{|l|}{ Education, $\mathrm{n}(\%)$} \\
\hline Less than college & $127(13.9)$ & $13(8.4)$ & .063 \\
\hline Some college & $279(30.5)$ & $42(27.3)$ & \\
\hline College graduate or postgraduate & $508(55.6)$ & $99(64.3)$ & \\
\hline White race, $\mathrm{n}(\%)$ & $801(87.9)$ & $125(81.2)$ & .028 \\
\hline Patients assigned to newly hired doctors & $48(5.1)$ & $105(65.6)$ & $<.001$ \\
\hline \multicolumn{4}{|l|}{ Self-reported health status, $n(\%)$} \\
\hline Excellent or very good & $461(51.8)$ & $80(53.7)$ & .633 \\
\hline Good & $302(33.9)$ & $52(34.9)$ & \\
\hline Fair or poor & $127(14.3)$ & $17(11.4)$ & \\
\hline \multicolumn{4}{|l|}{ ACES-SF subscales, ${ }^{b}$ mean (SD) } \\
\hline Quality of doctor-patient interactions & $85.8(16.3)$ & $85.1(16.4)$ & .627 \\
\hline Shared decision making & $85.1(22.3)$ & $84.8(21.7)$ & .883 \\
\hline Coordination of care & $81.3(21.5)$ & $79.4(22.6)$ & .327 \\
\hline Access & $87.1(17.2)$ & $86.3(19.3)$ & .645 \\
\hline Helpfulness of office staff & $91.4(15.6)$ & $92.3(13.0)$ & .499 \\
\hline \multicolumn{4}{|l|}{ PACIC subscales, ${ }^{b}$ mean (SD) } \\
\hline Patient activation/involvement & $77.7(27.0)$ & $72.7(29.7)$ & .056 \\
\hline Goal setting/tailoring & $69.0(30.8)$ & $69.4(31.3)$ & .893 \\
\hline \multicolumn{4}{|c|}{ Utilization measures (contacts per person in 2006) } \\
\hline Eligible patients from automated data & 6,188 & 1,817 & \\
\hline Primary care visits, mean (SD) & $3.67(4.40)$ & $2.44(2.92)$ & $<.001$ \\
\hline $\begin{array}{l}\text { Emergency department/urgent care visits, } \\
\text { mean (SD) }\end{array}$ & $0.374(0.978)$ & $0.241(0.694)$ & $<.001$ \\
\hline Secure message threads, mean (SD) & $1.29(3.46)$ & $0.85(2.96)$ & $<.001$ \\
\hline Telephone encounters, mean (SD) & $3.74(6.10)$ & $1.89(3.48)$ & $<.001$ \\
\hline \multicolumn{4}{|c|}{ ACES-SF = Ambulatory Care Experiences Survey-Short Form; PACIC = Patient Assessment of Chronic Illness Care. } \\
\hline \multicolumn{4}{|c|}{$\begin{array}{l}\text { a } P \text { value from } \chi^{2} \text { test comparing percentages and from } t \text { test comparing means between reassigned and not reas- } \\
\text { signed patients. } \\
\text { b The ACES-SF and PACIC questions (scored on } 6 \text { - and } 5 \text {-point Likert scales, respectively) were totaled within the } \\
\text { subscales and then transformed to } 100 \text {-point summary scores. }\end{array}$} \\
\hline
\end{tabular}

plex conditions. Yet, physicians did just that, preserving the continuity of care for patients to whom it likely matters most.

For those patients who were reassigned, however, the outcomes were not so positive. Patients who were less connected with a physician were more likely to be reassigned. Those reassigned patients used primary care services less often but appear to have used expensive emergency department visits as often as their counterparts. The decrease in primary care, after controlling for past usage, is worrisome, as one of the goals of a medical home implementation is to strengthen the connection between patients and their primary care physician to prevent episodes requiring emergency care. It is unclear whether this decrease in primary care usage represents a transitory effect of reassigning patients to new physician or a long-term disruption to relational continuity.

Interestingly, with this disruption of the patients' already tenuous doctor-patient relationship, we detected no significant impact on reassigned patients' care experience. Further, many of the differences in other measured domains were small given that one group suffered discontinuity with its primary care physicians.

Data limitations may have influenced the findings. First, we were unable to distinguish between patients who were ineligible for reassignment and those who were eligible but not randomly selected for reassignment. Baseline differences between these patients may have resulted in confounding. To address these concerns, sensitivity analyses were conducted. We excluded from the analysis those 
Table 2. Contrast in Adjusted Patient Experience and Utilization at 12 Months Between Not Reassigned and Reassigned Patients

\begin{tabular}{|c|c|c|c|c|}
\hline Characteristic & $\begin{array}{l}\text { Not Reassigned } \\
\text { Estimate (Cl) }\end{array}$ & $\begin{array}{l}\text { Reassigned } \\
\text { Estimate (Cl) }\end{array}$ & $\begin{array}{l}\text { Mean Difference }^{a} \\
\text { Estimate (Cl) }\end{array}$ & $P$ Value \\
\hline \multicolumn{5}{|l|}{ Patient experience } \\
\hline \multicolumn{5}{|l|}{ Ambulatory Care Experiences Survey (ACES-SF) ${ }^{\mathrm{b}}$} \\
\hline Quality of doctor-patient interactions & 86.1 (84.9 to 87.2 ) & $86.9(83.5$ to 90.4$)$ & $0.88(-2.99$ to 4.75$)$ & .656 \\
\hline Shared decision making & 86.4 (84.7 to 88.2$)$ & 84.0 (78.0 to 90.0$)$ & $-2.51(-9.20$ to 4.19$)$ & .462 \\
\hline Coordination of care & $82.0(80.2$ to 83.8$)$ & 80.3 (75.1 to 85.4$)$ & $-1.76(-7.63$ to 4.12$)$ & .558 \\
\hline Access & 86.8 (85.5 to 88.2$)$ & 85.3 (81.3 to 89.2$)$ & $-1.57(-5.94$ to 2.79$)$ & .479 \\
\hline Helpfulness of office staff & 90.9 (89.5 to 92.3$)$ & 88.7 (84.6 to 92.8$)$ & $-2.14(-6.77$ to 2.48$)$ & .363 \\
\hline \multicolumn{5}{|l|}{$\begin{array}{l}\text { Patient Assessment of Chronic Illness Care } \\
\text { survey }(\mathrm{PAClC})^{\mathrm{b}}\end{array}$} \\
\hline Activation & $81.1(79.0$ to 83.1$)$ & 80.0 (74.7 to 85.4$)$ & $-1.03(-7.19$ to 5.13$)$ & .743 \\
\hline Goal setting & 74.0 (71.7 to 76.3$)$ & 73.9 (67.6 to 80.1$)$ & $-0.15(-7.30$ to 7.00$)$ & .967 \\
\hline Utilization (contacts per person per year) & & & $\begin{array}{l}\% \text { Difference } \\
\text { Estimate }^{c}(\mathrm{Cl})\end{array}$ & \\
\hline Primary care visits & $3.00(2.93$ to 3.08$)$ & $2.67(2.53$ to 2.83$)$ & $-10.9(-16.7$ to -4.7$)$ & .001 \\
\hline Emergency department/urgent care visits & 0.295 (0.279 to 3.12$)$ & 0.324 (0.289 to 0.363$)$ & $9.8(-4.2$ to 25.8$)$ & .181 \\
\hline Secure message threads & $2.28(2.20$ to 2.36$)$ & 2.42 (2.26 to 2.59$)$ & $6.1(-2.3$ to 15.2$)$ & .157 \\
\hline Telephone encounters & 2.84 (2.74 to 2.94$)$ & 2.82 (2.63 to 3.03 ) & $-0.6(-9.7$ to 8.1$)$ & .884 \\
\hline \multicolumn{5}{|l|}{$\mathrm{Cl}=$ confidence interval. } \\
\hline \multicolumn{5}{|c|}{$\begin{array}{l}\text { a Adjusted mean difference and P value from linear regression with cluster-adjusted standard errors. Comparisons are between reassigned and not reassigned patients, } \\
\text { over } 12 \text {-month patient experience measures adjusting for sex, age, educational attainment, self-reported health status at baseline, assignment to new vs existing phys- } \\
\text { cian, and } 2006 \text { patient experience. } \\
\text { b The ACES-SF and PACIC questions (scored on 6- and 5-point Likert scales, respectively) were totaled within the subscales and then transformed to 100-point summary scores. } \\
\text { c Adjusted percent difference and P value from a generalized linear model with a log link and Poisson variance, adjusting for overdispersion. Comparisons are between } \\
\text { reassigned and not reassigned patients, over 12-month utilization adjusting for sex, age, morbidity, duration of relationship with primary care physician, assignment to } \\
\text { new vs existing physician and } 2006 \text { utilization. }\end{array}$} \\
\hline
\end{tabular}

patients that likely comprised a large portion of the population physicians' deemed ineligible for reassignment-those older than 65 years, those with a DxCG score greater than 2.5 , and those with a physician relationship lasting more than 8 years (data not shown). We remained unable to find significant relationships among any of the survey-administered scales. Because this represents a subanalysis, we may be underpowered to detect differences in patient's experiences of care as a result of reassignment. In addition, the unique patient characteristics of this single site may limit the generalizability of these findings to other clinical settings.

Contextualizing the clinical impact of these changes is difficult, as previous studies have shown conflicting results: Pereria and colleagues found that quality of care did not deteriorate for patients who were reassigned to new physicians, but Flocke et al showed that forced discontinuity led to significantly worse patient-perception of care. ${ }^{38,39}$ Because reassignment at Group Health happened within the context of a single clinic, the strength of informational and managerial continuity from the single electronic medical record that was coincidentally developed as part of the medical home intervention may have helped to mitigate the deleterious effects of disrupted relational continuity for reassigned patients. To ensure that practices do not adversely affect their relationships with younger, healthier patients as they work to strengthen existing doctor-patient relationships, more must be done proactively to bind patients to their new physicians and practice teams after being reassigned. Meaningfully adjoining patients and providers in the context of the medical home has the potential to create relational continuity for those who may not have it while strengthening existing relationships.

To read or post commentaries in response to this article, see it online at http://www.annfammed.org/cgi/content/full/8/6/493.

Key words: Patient-centered medical home; primary health care; continuity of patient care; physician-patient relations; patient-centered care

Submitted October 13, 2009; submitted, revised, August 3, 2010; accepted August 16, 2010.

Funding support: This project was supported by the Group Health Research Institute Development Fund and the Robert Wood Johnson Foundation Improving Chronic Illness Care: Scientific Support Grant no. 58194.

Acknowledgments: Researchers and staff at the Group Health Research Institute were involved in the design and conduct of the evaluation as well as in the collection, management, analysis, and interpretation of the evaluation data. We would especially like to thank Kelly Ehrlich, MS, for project management; Alicia Eng, RN, MBA, MHA, for verifying the empanelment protocol; and Rick Perrault for manuscript preparation. 


\section{References}

1. McGlynn EA, Asch SM, Adams J, et al. The quality of health care delivered to adults in the United States. N Engl J Med. 2003;348 (26):2635-2645

2. Ostbye T, Yarnall KS, Krause KM, Pollak KI, Gradison M, Michener $\mathrm{JL}$. Is there time for management of patients with chronic diseases in primary care? Ann Fam Med. 2005;3(3):209-214.

3. Roter DL, Hall JA. Studies of doctor-patient interaction. Annu Rev Public Health. 1989;10:163-180.

4. Schillinger D, Piette J, Grumbach K, et al. Closing the loop: physician communication with diabetic patients who have low health literacy. Arch Intern Med. 2003;163(1):83-90.

5. Yarnall KS, Pollak KI, OStbye T, Krause KM, Michener JL. Primary care: is there enough time for prevention? Am J Public Health. 2003;93(4):635-641.

6. Barr MS. The need to test the patient-centered medical home. JAMA. 2008;300(7):834-835.

7. Fisher ES. Building a medical neighborhood for the medical home. N Engl J Med. 2008;359(12):1202-1205.

8. Iglehart JK. No place like home-testing a new model of care delivery. N Engl J Med. 2008;359(12):1200-1202.

9. Kellerman R, Kirk L. Principles of the patient-centered medical home. Am Fam Physician. 2007;76(6):774-775.

10. Rosenthal TC. The medical home: growing evidence to support a new approach to primary care. J Am Board Fam Med. 2008;21(5): 427-440.

11. Sidorov JE. The patient-centered medical home for chronic illness: is it ready for prime time? Health Aff (Millwood). 2008;27(5):1231-1234

12. Jaen $C R$, Ferrer RL, Miller WL, et al. Patient outcomes at 26 months in the patient-centered medical home National Demonstration Project. Ann Fam Med. 2010;8(Suppl 1):S57-67; S92.

13. Gilfillan RJ, Tomcavage J, Rosenthal MB, et al. Value and the medical home: effects of transformed primary care. Am J Manag Care. 2010;16(8):607-614

14. American Academy of Family Physicians. Joint principles of the Patient-Centered Medical Home. Del Med J. 2008;80(1):21-22.

15. Berenson RA, Hammons T, Gans DN, et al. A house is not a home: keeping patients at the center of practice redesign. Health Aff (Millwood). 2008;27(5):1219-1230.

16. Rittenhouse DR, Casalino LP, Gillies RR, Shortell SM, Lau B. Measuring the medical home infrastructure in large medical groups. Health Aff (Millwood). 2008;27(5):1246-1258.

17. Marx R, Drennan MJ, Johnson EC, Solnit SA, Hirozawa AM, Katz $\mathrm{MH}$. Creating a medical home in the San Francisco department of public health: establishing patient panels. J Public Health Manag Pract. 2009;15(4):337-344.

18. Reid RJ, Fishman PA, Yu O, et al. Patient-centered medical home demonstration: a prospective, quasi-experimental, before and after evaluation. Am J Manag Care. 2009;15(9):e71-e87.

19. Reid RJ, Coleman K, Johnson EA, et al. The Group Health medical home at year two: cost savings, higher patient satisfaction, and less burnout for providers. Health Aff (Millwood). 2010;29(5):835-843.

20. Nutting PA, Miller WL, Crabtree BF, Jaen $C R$, Stewart EE, Stange KC. Initial lessons from the first national demonstration project on practice transformation to a patient-centered medical home. Ann Fam Med. 2009;7(3):254-260.
21. Reid RJ, Haggerty J, McKendry R. Defusing the Confusion: Concepts and Measures of Continuity of Healthcare. Ottawa, ON: Canadian Health Services Research Foundation; 2002.

22. Haggerty JL, Reid RJ, Freeman GK, Starfield BH, Adair CE, McKendry R. Continuity of care: a multidisciplinary review. BMJ. 2003; 327(7425):1219-1221.

23. Hjortdahl P, Laerum E. Continuity of care in general practice: effect on patient satisfaction. BMJ. 1992;304(6837):1287-1290.

24. Berry LL, Parish JT, Janakiraman R, et al. Patients' commitment to their primary physician and why it matters. Ann Fam Med. 2008; 6(1):6-13.

25. Saultz JW, Lochner J. Interpersonal continuity of care and care outcomes: a critical review. Ann Fam Med. 2005;3(2):159-166.

26. Weiss LJ, Blustein J. Faithful patients: the effect of long-term physician-patient relationships on the costs and use of health care by older Americans. Am J Public Health. 1996;86(12):1742-1747.

27. De Maeseneer JM, De Prins L, Gosset C, Heyerick J. Provider continuity in family medicine: does it make a difference for total health care costs? Ann Fam Med. 2003;1(3):144-148.

28. DxCG Inc. DxCG RiskSmart Clinical Classifications Guide. Boston, MA: DxCG Inc; 2007.

29. Bice TW, Boxerman SB. A quantitative measure of continuity of care. Med Care. 1977;15(4):347-349.

30. Steinwachs DM. Measuring provider continuity in ambulatory care: an assessment of alternative approaches. Med Care. 1979;17(6): 551-565.

31. Safran DG, Karp M, Coltin K, et al. Measuring patients' experiences with individual primary care physicians. Results of a statewide demonstration project. J Gen Intern Med. 2006;21(1):13-21.

32. Rodriguez HP, von Glahn T, Rogers WH, Chang H, Fanjiang G, Safran DG. Evaluating patients' experiences with individual physicians: a randomized trial of mail, internet, and interactive voice response telephone administration of surveys. Med Care. 2006;44(2):167-174.

33. Glasgow RE, Wagner EH, Schaefer J, Mahoney LD, Reid RJ, Greene SM. Development and validation of the Patient Assessment of Chronic Illness Care (PACIC). Med Care. 2005;43(5):436-444.

34. Hjortdahl P. Continuity of care: general practitioners' knowledge about, and sense of responsibility toward their patients. Fam Pract. 1992;9(1):3-8

35. Stokes T, Tarrant C, Mainous AG III, Schers H, Freeman G, Baker R. Continuity of care: is the personal doctor still important? A survey of general practitioners and family physicians in England and Wales, the United States, and The Netherlands. Ann Fam Med. 2005;3(4):353-359.

36. Viera AJ, Pathman DE, Garrett JM. Adults' lack of a usual source of care: a matter of preference? Ann Fam Med. 2006;4(4):359-365.

37. Nutting PA, Goodwin MA, Flocke SA, Zyzanski SJ, Stange KC. Continuity of primary care: to whom does it matter and when? Ann Fam Med. 2003;1(3):149-155.

38. Flocke SA, Stange KC, Zyzanski SJ. The impact of insurance type and forced discontinuity on the delivery of primary care. J Fam Pract. 1997;45(2):129-135.

39. Pereira AG, Kleinman KP, Pearson SD. Leaving the practice: effects of primary care physician departure on patient care. Arch Intern Med. 2003;163(22):2733-2736. 